\title{
Article
}

\section{Applicability of the Leiden Convention and the Lipton Classification in Patients with a Single Coronary Artery in the Setting of Congenital Heart Disease}

\author{
Diana Isabel Katekaru-Tokeshi ${ }^{1}{ }^{\mathbb{D}}$, Moisés Jiménez-Santos ${ }^{2}$, Claire J. Koppel ${ }^{3}$, Hubert W. Vliegen ${ }^{3}$, \\ Mariana Díaz-Zamudio ${ }^{2}$, Francisco Castillo-Castellón ${ }^{2}$, Monique R. M. Jongbloed ${ }^{3,4}$ (D) \\ and Eric Kimura-Hayama ${ }^{2, *}$
}

check for updates

Citation: Katekaru-Tokeshi, D.I.; Jiménez-Santos, M.; Koppel, C.J.; Vliegen, H.W.; Díaz-Zamudio, M.; Castillo-Castellón, F.; Jongbloed, M.R.M.; Kimura-Hayama, E. Applicability of the Leiden Convention and the Lipton Classification in Patients with a Single Coronary Artery in the Setting of Congenital Heart Disease. J. Cardiovasc. Dev. Dis. 2021, 8, 93. https://doi.org/10.3390/jcdd8080093

Academic Editor: Andy Wessels

Received: 27 June 2021

Accepted: 29 July 2021

Published: 4 August 2021

Publisher's Note: MDPI stays neutral with regard to jurisdictional claims in published maps and institutional affiliations.

Copyright: (c) 2021 by the authors. Licensee MDPI, Basel, Switzerland. This article is an open access article distributed under the terms and conditions of the Creative Commons Attribution (CC BY) license (https:/ / creativecommons.org/licenses/by/ $4.0 /)$.
1 Service of Cardiology, Hospital Nacional Dos de Mayo, Lima 150101, Peru; diakatekaru@hotmail.com

2 Departament of Radiology, Service of Computed Tomography, Instituto Nacional de Cardiologia Ignacio Chavez, Juan Badiano 1, Col. Seccion XVI, Mexico City 14080, Mexico; mjimenez@ctcardiomexico.com (M.J.-S.); diazzmariana@gmail.com (M.D.-Z.); fcastillo@ctcardiomexico.com (F.C.-C.)

3 Department of Cardiology, Leiden University Medical Center, Albinusdreef 2, Postal Zone B-04-P, 2300 RC Leiden, The Netherlands; C.J.Koppel@lumc.nl (C.J.K.); h.w.vliegen@lumc.nl (H.W.V.); M.R.M.Jongbloed@lumc.nl (M.R.M.J.)

4 Department of Anatomy and Embryology, Leiden University Medical Center, Einthovenweg 20, Postal Zone S-1-P, 2300 RC Leiden, The Netherlands

* Correspondence: erickimura@ctcardiomexico.com; Tel.: +52-55732911

\begin{abstract}
Abstract: BackgroundIn single coronary artery (SCA) anatomy, all coronary tributaries arise from a single ostium, providing perfusion to the entire myocardium. Coronary classification systems can facilitate the description of SCA anatomy. Aim: Evaluation of the applicability of Lipton classification and the Leiden Convention coronary coding system in SCA. Methods: All patients ( $n=6209$ ) who underwent computed tomography (CT) scanning between 2014 and 2018 were retrospectively examined for the presence of SCA and classified, according to Lipton classification and the Leiden Convention coronary coding system. Results: The prevalence of SCA was $0.51 \%$ (32/6209). Twenty-eight patients $(87.5 \%)$ had coexisting congenital heart disease (CHD), most frequently pulmonary atresia $(9 / 32,28.1 \%)$. Ten patients $(10 / 32,31.25 \%)$ could not be classified with either the Leiden Convention or Lipton classification (pulmonary atresia $n=9$, common arterial trunk (CAT) $n=1$ ). In one case with CAT, Lipton classification, but not the Leiden Convention, could be applied. In two cases with the transposition of the great arteries and in two cases of double outlet right ventricle, the Leiden Convention, but not the Lipton classification, could be applied. Conclusions: Both classifications are useful to detail information about SCA. As Lipton classification was not developed for structural heart disease cases, in complex CHD with abnormal position of the great arteries, the Leiden Convention is better applicable. The use of both systems is limited in pulmonary atresia. In this scenario, it is better to provide a precise description of the coronary origin and associated characteristics that might affect treatment and prognosis.
\end{abstract}

Keywords: single coronary artery; Leiden Convention coronary coding system; Lipton classification; coronary artery anatomy; congenital heart disease

\section{Introduction}

In single coronary artery (SCA) anatomy, all coronary tributaries arise from a single ostium, providing perfusion to the entire myocardium [1,2]. The prevalence reported in the general population is $0.024 \%$ to $0.066 \%$, diagnosed by invasive coronary angiography [1] SCA has been associated with other congenital heart disease (CHD) in 40\% of cases [2].

As variations in origin and course are common, classification systems have been developed to facilitate anatomical description. 
In 1979, Lipton described a SCA classification system based on the origin, branching pattern, and course of the coronary artery [2]. The classification system describes coronary anatomy according to predefined patterns. In 1990, the system was modified by Yamanaka and Hobbs to include a septal course [3] (Figure 1). SCAs originating from the anatomical right or left sinus are indicated by an $\mathrm{R}$ and $\mathrm{L}$, respectively, followed by the numerical category of the branching pattern (I-III). In Lipton classification, an origin of the coronary artery from the posterior sinus is not included. The classification was not primarily developed, however, for CHD with abnormally aligned great vessels.

\section{Group I}

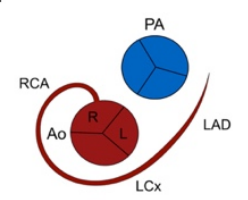

RI

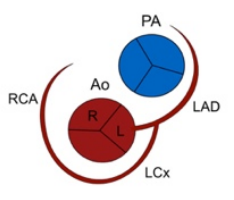

LI

Group II

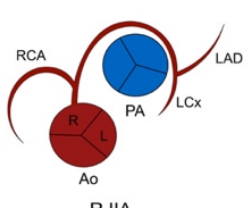

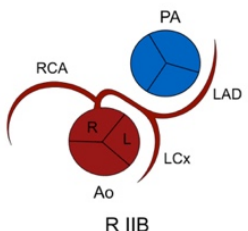

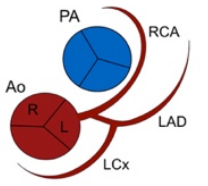

LIIA
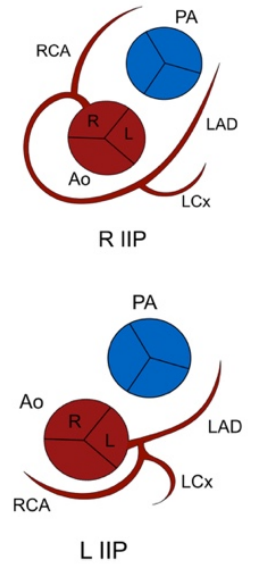
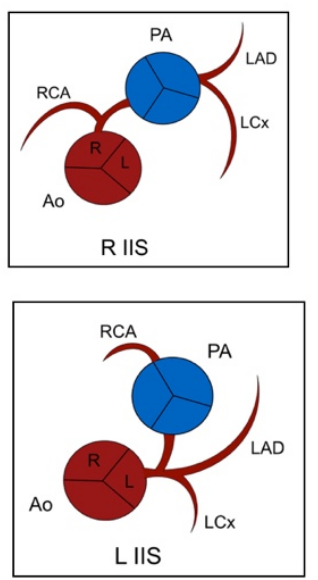

\section{Group III}

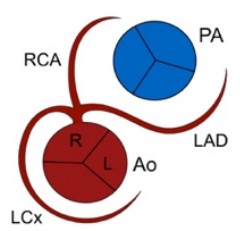

R III

Figure 1. Classification of SCA by Lipton and modified by Yamanaka and Hobbs (marked). Viewed from caudal to cranial, "imaging view". Ao: Aorta. L: Left sinus of Valsalva. LAD: Left anterior descending artery. LCx: Left circumflex artery. PA: Pulmonary artery. R: Right sinus of Valsalva. RCA: Right coronary artery.

The imaging Leiden Convention coronary is a coronary coding system that was developed in the 1980s by Prof. Dr. Adriana Gittenberger-de Groot [4,5]. It can be used in cases with variable and complicated coronary patterns and has the advantage that it can be used irrespective of the position of the great arteries. The system approaches the coronary anatomy based on the fact that both great arteries have, in principle, two "facing" sinuses (Figure 2). Therefore, it applies in structurally normal hearts as well as in CHD, including bicuspid aortic valves. The system avoids using terms related to the spatial orientation of the arterial origin from the aorta in the description, and designates the aortic sinuses as "left or right facing" or "non-facing" relative to the pulmonary valve sinuses. This is based 
on the principle that the non-facing sinus (corresponding to the posterior sinus in the case of a normal position of the great arteries), will never carry a coronary artery. Originally, the system was developed for use by cardiac surgeons but was recently extended to provide its use by interventional and imaging (pediatric) cardiologists as well $[5,6]$. To correct for the different angles at which the coronary arteries are viewed by surgeons and imaging cardiologists, the methods to acquire the same annotation are slightly different for the imaging than for the surgical perspective of the Leiden Convention coding system. For the imaging view, the physician positions themselves in the non-facing sinus of the aortic valve, looking out from the sinus. Positioned in this way, the right-hand sinus is sinus 1 , and the left-hand sinus is sinus 2 . Then, the branches are described in the order in which they are encountered when adopting a clockwise rotation starting at sinus $1[5,6]$ (Figure 2). To our knowledge, there are no studies that evaluate the applicability of the two classification systems (i.e., Lipton classification and the Leiden Convention coronary coding system) for classification of single coronary arteries in the setting of complex congenital heart disease. The aims of the present study are (1) to report the prevalence of cases of SCA diagnosed by coronary computed tomography angiography (CCTA) in a tertiary healthcare cardiovascular center and (2) to evaluate the applicability of Lipton classification and the imaging Leiden Convention coronary coding system to annotate the SCA anatomy.

\section{The Leiden Convention}

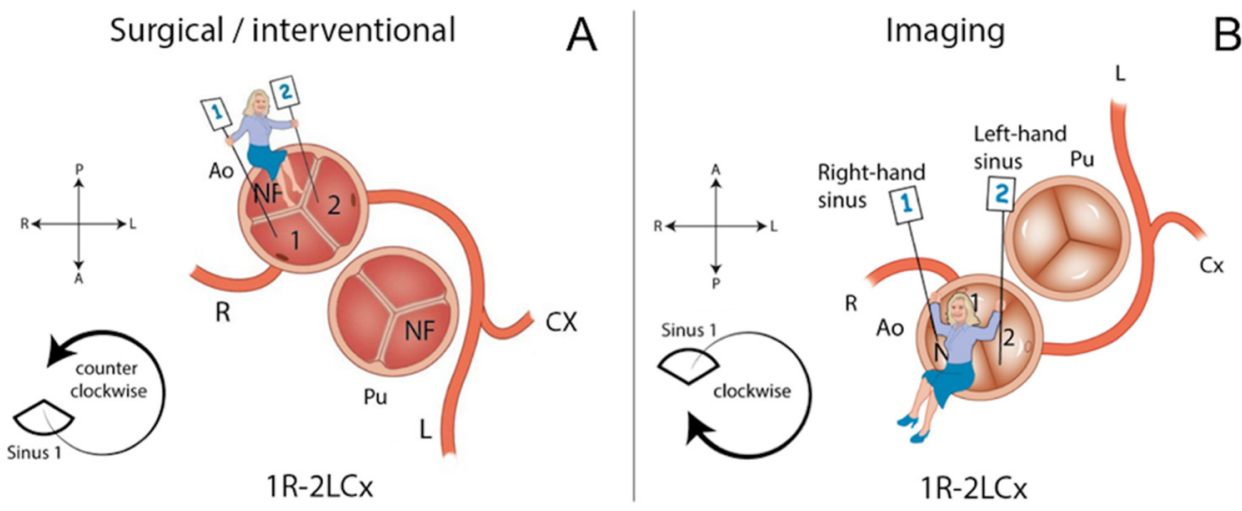

Figure 2. The Leiden Convention considers a surgical/interventional or an imaging perspective (Figure derived with permission from Koppel et al. [6]). (A) Surgical/Interventional Leiden Convention. In this method, the coronary anatomy is examined from above, as a surgeon would see it during surgery. The physician sits in the non-facing sinus, facing the pulmonary valve. In that position, the sinus on the right is sinus 1 and the sinus on the left is sinus 2. Starting from sinus 1 , the coronary branches are named in the order that they are encountered when following a counterclockwise rotation. (B) Imaging Leiden Convention. The physician's view on the coronary anatomy is from the base of the aorta upward. The physician sits in the non-facing sinus of the aortic valve, facing outward from the sinus. From this position, the right-hand sinus is again sinus 1, and the left-hand sinus is sinus 2 . Following a clockwise rotation, starting at sinus 1, the encountered coronary branches are annotated. A: Anterior. Ao: Aorta. L: Left. NF: Non-facing sinus. P: Posterior. Pu: Pulmonary. R: Right.

\section{Materials and Methods}

Consecutive patients that were scanned between March 2014 and January 2018 in a tertiary referral center were evaluated for the presence of SCA. We employed a dual-source 256-MDCT scanner (Definition Flash, Siemens Healthineers, Erlangen, Germany) with a sectional collimation of $2 \times 128 \times 0.6$. Either ECG-gated or non-ECG-gated high-pitch protocols were used (pitch factor of 0.17 and 3.4 respectively), at the discretion of the attending physician, taking into account the patient's ability to follow instructions, clinical condition and request. The indication for the CCTA in pediatric patients $(24 / 32,75 \%)$ was to further investigate previously diagnosed CHD. The indication for the CCTA in the adult patients $(8 / 32,25 \%)$ was to rule out coronary artery disease. In cardiac-gated scans, 
a prospective acquisition was triggered in systole (40-45\% of R-R interval). X-ray tube parameters of voltage and current were adjusted to patient's weight as follows: $80 \mathrm{kV}$ if less than $20 \mathrm{~kg}$ and $100 \mathrm{kV}$ if BMI $<25$ or weight $20-80 \mathrm{~kg}$, with a current of $10 \mathrm{~mA} / \mathrm{kg}$ (up to $9 \mathrm{~kg}$ ) and $5 \mathrm{~mA}$ for each additional $\mathrm{kg}$. A current $z$-modulation technique (CARE-Dose, Siemens Healthinneers) was used in all patients. The FOV extended from the carina to the lower portion of the heart. The contrast transit time was determined with the use of a bolus tracking technique by placing the region of interest in the ascending aorta. Images were reconstructed in $0.75 \mathrm{~mm}$ thickness and interval reconstruction with a B25f kernel filter.

We used non-ionic contrast material (iobitridol, Guerbet, Roissy, France) at a volume of 1-1.5 mL/ kg of body weight for non-gated scans or 1.5-2 mL/kg for ECG-gated acquisitions. All images were analyzed by an imaging cardiologist with 8 years of experience in adult and pediatric cardiovascular imaging (MJS). Afterwards, the coronary anatomy was also reviewed and annotated by CJK. Dedicated cardiac workstations were used (Syngo Via v2.0, Siemens Healthineers, Forcheim, Germany and Vitrea, Vital images, Inc., Minnetonka, MN, USA., resp.), capable of multiplanar and volume rendering reformations. An institutional review board (IRB) consent form was obtained the time that CCTA was performed. The average dose length product (DLP) was $142.5 \mathrm{mGy}-\mathrm{cm}(16-426 \mathrm{mGy}-\mathrm{cm})$.

\section{Results}

The prevalence of SCA diagnosed by CCTA was $0.51 \%(32 / 6209)$ in this tertiary cardiovascular referral center. Twenty patients were female $(62.5 \%)$; the median age was 16 years and 7 months (range 1 month to 78 years) (Table 1 ).

Ten patients $(31.25 \%)$ presented with a concomitant coronary anatomy anomaly (CAA), including an anomalous origin of a right coronary artery (RCA) from the left anterior descending coronary artery (LAD) (Figure 3$)(6 / 32,18.75 \%)$ and an absent RCA (4/32, $12.5 \%)$. Of the 32 included patients, $4(12.5 \%)$ showed an interarterial course.

Table 1. Patients' demographics, associated congenital heart disease, imaging Leiden Convention and Lipton classification.

\begin{tabular}{|c|c|c|c|c|c|c|c|}
\hline $\begin{array}{l}\text { Patient } \\
\text { Number }\end{array}$ & Gender & Age & Associated Anomalies & $\begin{array}{c}\text { Anatomical } \\
\text { Relationship of } \\
\text { the Ao to the PA }\end{array}$ & $\begin{array}{l}\text { Leiden } \\
\text { Convention }\end{array}$ & $\begin{array}{c}\text { Lipton } \\
\text { Classification }\end{array}$ & $\begin{array}{c}\text { Concomitant } \\
\text { Coronary } \\
\text { Anomaly }\end{array}$ \\
\hline 1 & M & $1 \mathrm{M}$ & $\begin{array}{l}\text { Double-outlet right } \\
\text { ventricle }\end{array}$ & Right anterior & $2 \mathrm{LCx}$ & LI & Absent RCA \\
\hline 2 & $\mathrm{~F}$ & $2 \mathrm{M}$ & $\begin{array}{l}\text { Truncus arteriosus Van } \\
\text { Praagh type A4 }\end{array}$ & NA & NA & $\mathrm{NI}^{*}$ & None \\
\hline 3 & $\mathrm{~F}$ & $6 \mathrm{M}$ & $\begin{array}{l}\text { Pulmonary atresia. Single } \\
\text { outlet right ventricle. Right } \\
\text { aortic arch. }\end{array}$ & NA & NA & $\mathrm{NI}^{*}$ & None \\
\hline 4 & $\mathrm{~F}$ & $6 \mathrm{M}$ & $\begin{array}{l}\text { Pulmonary atresia. Single } \\
\text { outlet right ventricle. }\end{array}$ & NA & NA & $\mathrm{NI}^{*}$ & None \\
\hline 5 & $\mathrm{~F}$ & $8 \mathrm{M}$ & $\begin{array}{c}\text { Transposition of the great } \\
\text { arteries }\end{array}$ & Left anterior & 2CxRL & $\mathrm{NI}^{*}$ & None \\
\hline 6 & $\mathrm{~F}$ & $3 Y$ & Tetralogy of Fallot & $\begin{array}{l}\text { Clockwise rotation } \\
\text { of the aortic root }\end{array}$ & 2RLCx & LIIA & $\begin{array}{l}\text { Anomalous } \\
\text { origin of RCA } \\
\text { from LAD }\end{array}$ \\
\hline 7 & M & $3 Y$ & $\begin{array}{c}\text { Double-outlet right } \\
\text { ventricle. Common } \\
\text { atrioventricular canal type } \\
\text { C of Rastelli. Right aortic } \\
\text { arch }\end{array}$ & Left anterior & 1LCxR & $\mathrm{NI}^{*}$ & None \\
\hline 8 & $\mathrm{~F}$ & $4 Y$ & $\begin{array}{l}\text { Stenosis left ventricular } \\
\text { outflow tract by } \\
\text { fibromuscular protrusion }\end{array}$ & Right posterior & $2 \mathrm{LCx}$ & LI & Absent RCA \\
\hline 9 & M & $4 Y$ & Tetralogy of Fallot & $\begin{array}{l}\text { Clockwise rotation } \\
\text { of the aortic root }\end{array}$ & 2RLCx & LIIA & $\begin{array}{l}\text { Anomalous } \\
\text { origin of RCA } \\
\text { from LAD }\end{array}$ \\
\hline
\end{tabular}


Table 1. Cont.

\begin{tabular}{|c|c|c|c|c|c|c|c|}
\hline $\begin{array}{l}\text { Patient } \\
\text { Number }\end{array}$ & Gender & Age & Associated Anomalies & $\begin{array}{c}\text { Anatomical } \\
\text { Relationship of } \\
\text { the Ao to the PA }\end{array}$ & $\begin{array}{c}\text { Leiden } \\
\text { Convention }\end{array}$ & $\begin{array}{c}\text { Lipton } \\
\text { Classification }\end{array}$ & $\begin{array}{l}\text { Concomitant } \\
\text { Coronary } \\
\text { Anomaly } \\
\end{array}$ \\
\hline 10 & M & $4 \mathrm{Y}$ & $\begin{array}{c}\text { Pulmonary atresia. } \\
\text { Ambiguous atrioventricular } \\
\text { connection. Right aortic } \\
\text { arch }\end{array}$ & NA & NA & $\mathrm{NI}^{*}$ & None \\
\hline 11 & $\mathrm{~F}$ & $5 \mathrm{Y}$ & $\begin{array}{c}\text { Truncus arteriosus Van } \\
\text { Praagh type A1. Right } \\
\text { aortic arch }\end{array}$ & NA & NA & RIII & None \\
\hline 12 & $\mathrm{~F}$ & $5 Y$ & Syndrome Noonan & Right posterior & 2RLCx & LIIA & None \\
\hline 13 & $\mathrm{~F}$ & $6 \mathrm{Y}$ & $\begin{array}{l}\text { Double-outlet right } \\
\text { ventricle }\end{array}$ & Right anterior & $2 \mathrm{LCxR}$ & $\mathrm{NI}^{*}$ & None \\
\hline 14 & $\mathrm{~F}$ & $8 Y$ & Isolated & Right posterior & 1RLCx & RIIS & None \\
\hline 15 & $\mathrm{~F}$ & $9 \mathrm{Y}$ & $\begin{array}{l}\text { Double-outlet right } \\
\text { ventricle. Pulmonary } \\
\text { atresia }\end{array}$ & NA & NA & $\mathrm{NI}^{*}$ & None \\
\hline 16 & M & $10 \mathrm{Y}$ & Tetralogy of Fallot & $\begin{array}{l}\text { Clockwise rotation } \\
\text { of the aortic root }\end{array}$ & $1 R L C x$ & RIIA & None \\
\hline 17 & $\mathrm{~F}$ & $10 \mathrm{Y}$ & $\begin{array}{l}\text { Pulmonary agenesis. } \\
\text { Common atrioventricular } \\
\text { connection. Single outlet } \\
\text { right ventricle }\end{array}$ & NA & NA & $\mathrm{NI}^{*}$ & None \\
\hline 18 & $\mathrm{~F}$ & $11 Y$ & Pulmonary atresia & NA & NA & $\mathrm{NI}^{*}$ & None \\
\hline 19 & M & $12 Y$ & $\begin{array}{c}\text { Pulmonary agenesis. Single } \\
\text { outlet right ventricle. Right } \\
\text { aortic arch }\end{array}$ & NA & NA & $\mathrm{NI}^{*}$ & None \\
\hline 20 & $\mathrm{~F}$ & $13 Y$ & Mitral valve prolapse & Right posterior & $1 \mathrm{RL}^{*} \mathrm{Cx}$ & RIII & None \\
\hline 21 & M & $14 \mathrm{Y}$ & $\begin{array}{l}\text { Transposition of the great } \\
\text { arteries }\end{array}$ & Left anterior & $1 \mathrm{LCxR}$ & RIIP & None \\
\hline 22 & M & $15 Y$ & $\begin{array}{l}\text { Supravalvular aortic } \\
\text { stenosis }\end{array}$ & Right posterior & $2 \mathrm{R}^{*} \mathrm{LCx}$ & LIIB & None \\
\hline 23 & M & $15 \mathrm{Y}$ & Tetralogy of Fallot & $\begin{array}{l}\text { Clockwise rotation } \\
\text { of the aortic root }\end{array}$ & $2 R L C x$ & LIIA & $\begin{array}{l}\text { Anomalous } \\
\text { origin of RCA } \\
\text { from LAD }\end{array}$ \\
\hline 24 & M & $16 Y$ & $\begin{array}{c}\text { Transposition of the great } \\
\text { arteries }\end{array}$ & Right anterior & $1 R L C x$ & $\mathrm{NI}^{*}$ & None \\
\hline 25 & $\mathrm{~F}$ & $18 \mathrm{Y}$ & Pulmonary atresia & NA & NA & $\mathrm{NI}^{*}$ & None \\
\hline 26 & $\mathrm{~F}$ & $25 Y$ & $\begin{array}{c}\text { Pulmonary atresia. Double } \\
\text { inlet left ventricle. Right } \\
\text { aortic arch }\end{array}$ & NA & NA & $\mathrm{NI}^{*}$ & None \\
\hline 27 & $\mathrm{~F}$ & $37 Y$ & $\begin{array}{l}\text { Atrial septal defect. } \\
\text { Ventricular septal defect }\end{array}$ & Right posterior & $2 \mathrm{R}^{*} \mathrm{LCx}$ & LIIB & $\begin{array}{l}\text { Anomalous } \\
\text { origin of RCA } \\
\text { from LAD }\end{array}$ \\
\hline 28 & $\mathrm{~F}$ & $51 Y$ & $\begin{array}{l}\text { Left ventricular } \\
\text { non-compaction }\end{array}$ & Right posterior & 2RLCx & LIIA & $\begin{array}{l}\text { Anomalous } \\
\text { origin of RCA } \\
\text { from LAD }\end{array}$ \\
\hline 29 & M & $52 Y$ & Isolated & Right posterior & $2 \mathrm{LCx}$ & LI & Absent RCA \\
\hline 30 & M & $53 Y$ & Dysplastic aortic valve & Right posterior & $2 \mathrm{LCx}$ & LI & Absent RCA \\
\hline 31 & M & $58 \mathrm{Y}$ & $\begin{array}{l}\text { Coronary artery disease. } \\
\text { Rupture of right sinus of } \\
\text { Valsalva aneurysm }\end{array}$ & Right posterior & 2LCxR & LIIP & None \\
\hline 32 & $\mathrm{~F}$ & $78 \mathrm{Y}$ & Isolated & Right posterior & 2RLCx & LIIA & $\begin{array}{l}\text { Anomalous } \\
\text { origin of RCA } \\
\text { from LAD }\end{array}$ \\
\hline
\end{tabular}




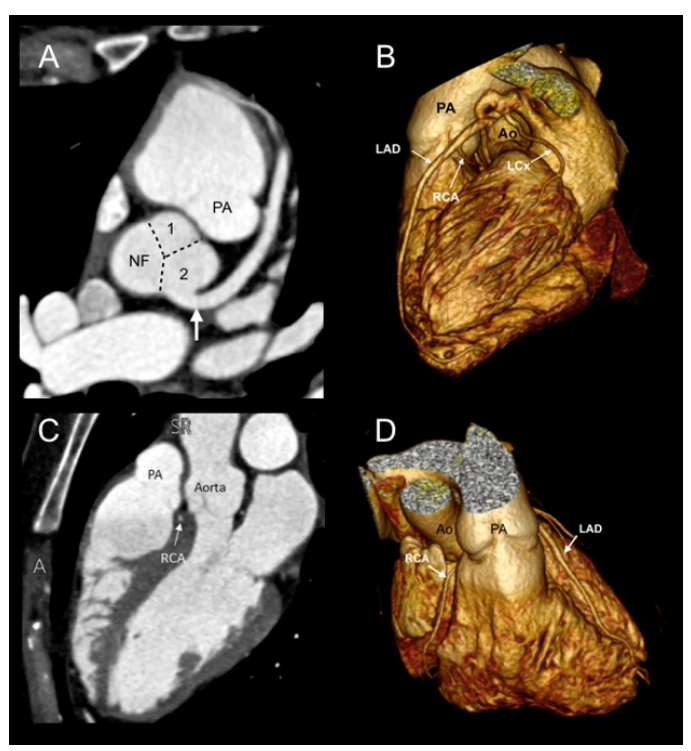

Figure 3. Case 27. CCTA in a 37-year-old woman undergoing preoperative evaluation for an atrial septal defect. (A) Axial image depicting the origin of the SCA (arrow) from sinus 2. (B) A 3D volumerendered image showing that the RCA originates from the middle segment of the LAD with an interarterial course. According to the Imaging Leiden Convention, the anatomy is $2 \mathrm{R}^{*} \mathrm{LCx}$; by Lipton classification, it is LIIB. (C,D) The RCA follows a course between the aorta and pulmonary artery (level of right ventricular outflow tract). Ao: Aorta. LAD: Left anterior descending coronary artery. LCx: Left circumflex. NF: Non-facing sinus. PA: Pulmonary artery. RCA: Right coronary artery.

Twenty-eight patients $(87.5 \%)$ had coexisting CHD (Table 1). The most frequent were pulmonary atresia/agenesis $(9 / 32,28.1 \%)$, one of which also had a double-outlet right ventricle, right aortic arch $(6 / 32,18.75 \%)$, double-outlet right ventricle $(4 / 32,12.5 \%)$, tetralogy of Fallot $(4 / 32,12.5 \%)$, and transposition of great arteries $(3 / 34,9.4 \%)$.

In our cohort, six patients $(18.75 \%)$ had an anomalous position of the great arteries in which the anatomical relationship of the aorta in relation to the pulmonary trunk was as follows: right anterior $3(9.4 \%)$ and left anterior $3(9.4 \%)$. Additionally, four patients with tetralogy of Fallot had clockwise rotation of the aortic root (Figure 4).

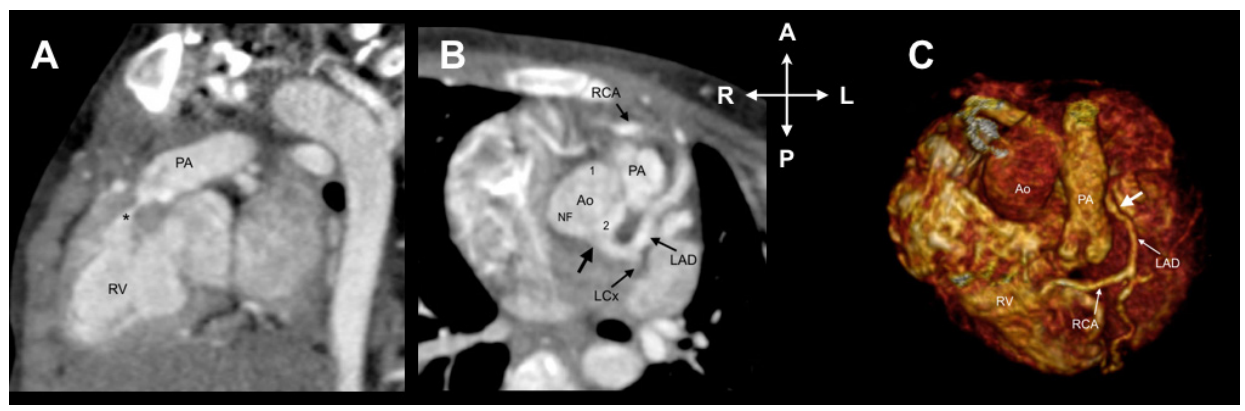

Figure 4. Case 9. A 4-year-old child with tetralogy of Fallot. (A) Oblique image showing infundibular pulmonary stenosis $\left(^{*}\right)$. (B) Axial image reveals coronary origins clockwise rotated along with the aortic root. According to the Leiden Convention, it is 2RLCx and by Lipton classification, it is LIIA. (C) A 3D volume-rendered image shows an anomalous origin of the RCA from the LAD. A: Anterior. Ao: Aorta. LAD: Left anterior descending coronary artery. L: Left. LCx: Left circumflex. P: Posterior. R: Right. RV: Right ventricle. NF: Non-facing sinus. PA: Pulmonary artery. RCA: Right coronary artery.

Of the adult patients, $(8 / 32,25 \%)$ the mean calcium score was 11.38 Agatston units (AU) (0-63.4 AU). 


\subsection{Lipton Classification}

The most common origin of the SCA was from the left anterior sinus of Valsalva $(13 / 32,50 \%)$, followed by an origin from the right anterior sinus of Valsalva $(5 / 32,15.6 \%)$, as observed from the anatomical position of the heart in the thorax. According to this system, these 18 patients were classified as LI $(n=4,22.2 \%)$, LIIA $(n=6,33.3 \%)$, LIIB $(n=2,11 \%)$, LIIP $(n=1,5.5 \%)$, RIIA $(n=1,5.5 \%), \operatorname{RIIP}(n=1,5.5 \%)$, RIIS $(n=1,5.5 \%)$ and RIII ( $\mathrm{n}=2,11 \%)$. However, 9 patients with CHD and abnormally aligned great vessels had a SCA origin from the anatomically posterior sinus and 4 with pulmonary atresia, and 1 patient with a common arterial trunk Van Praagh type A4 did not have a course around the pulmonary artery or right ventricular outflow tract, so could not be included in any category of the Lipton classification (Figure 5, Table 2).

Lipton classification not applicable

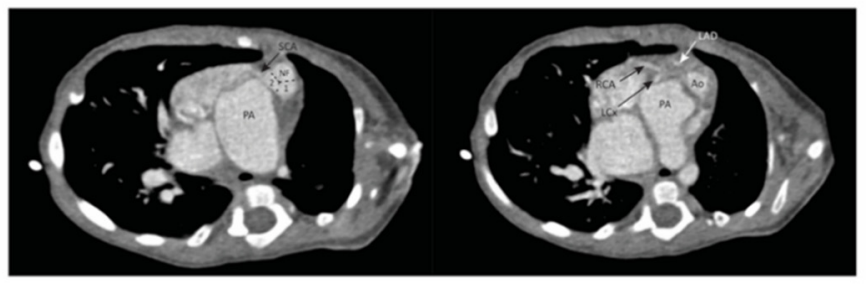

Case 5. Transposition of the great arteries. Leiden Convention 2CxRL. Lipton classification: coronary course not included.

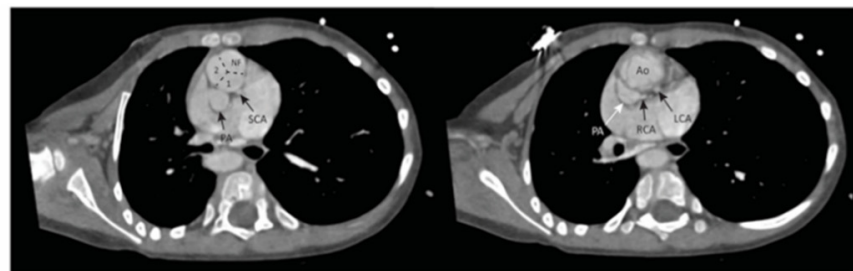

Case 7. Double outlet right ventricle. Leiden Convention 1LCxR. Lipton classification: not included, because origin SCA in sinus of Valsalva with posterior location.

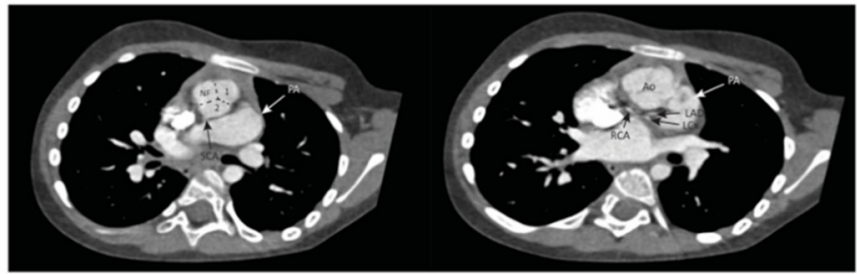

Case 13. Double outlet right ventricle. Leiden Convention:2LCXR. Lipton classification: Not included, because origin SCA in sinus of Valsalva with posterior location.

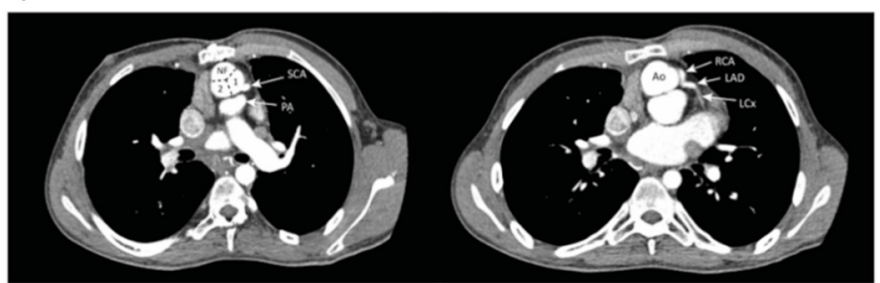

Case 24. Transposition of the great arteries. Leiden Convention: 1RLCx. Lipton classification: Not included, because origin SCA in sinus of Valsalva with posterior location.

\section{Leiden Convention not applicable}

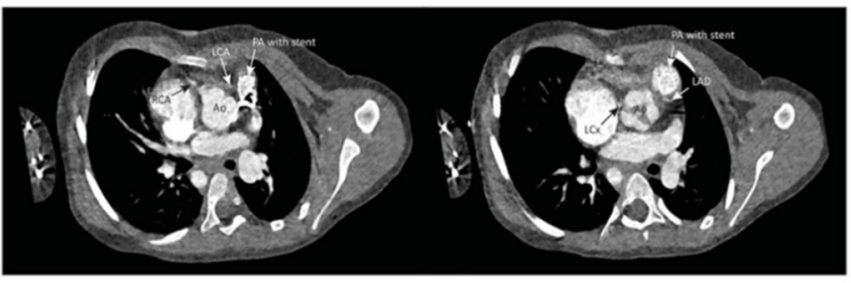

Case 11. Truncus arteriosus Van Praagh type A1. Leiden Convention not applicable. Lipton classification: RIII

Figure 5. Overview of cases that could be classified only with the Lipton classification or the Leiden Convention. Ao: Aorta. LAD: Left anterior descending coronary artery. LCx: Left circumflex. R: Right. NF: Non-facing sinus. PA: Pulmonary artery. RCA: Right coronary artery. SCA: Single coronary artery. 
Table 2. Overview of cases not assessable by either classification.

\begin{tabular}{|c|c|c|}
\hline & Lipton Classification & Leiden Convention \\
\hline Patient Number & \multicolumn{2}{|c|}{ Associated Anomaly Preventing Use of Both Classification Systems } \\
\hline 2 & Posterior sinus & Truncus arteriosus type A4 \\
\hline 3 & Posterior sinus & Pulmonary atresia \\
\hline 4 & Course not included & Pulmonary atresia \\
\hline 10 & Course not included & Pulmonary atresia \\
\hline 15 & Posterior sinus & Pulmonary atresia \\
\hline 17 & Posterior sinus & Pulmonary atresia \\
\hline 18 & Posterior sinus & Pulmonary atresia \\
\hline 19 & Course not included & Pulmonary atresia \\
\hline 5 & Course not included & Pulmonary atresia \\
\hline \multirow[t]{2}{*}{26} & Posterior sinus & Pulmonary atresia \\
\hline & \multicolumn{2}{|c|}{$\begin{array}{l}\text { Lipton classification applicable, Leiden Convention not applicable } \\
\text { (Figure 5) }\end{array}$} \\
\hline \multirow[t]{2}{*}{11} & RIII & Truncus arteriosus type A1 \\
\hline & \multicolumn{2}{|c|}{$\begin{array}{l}\text { Lipton classification not applicable, Leiden Convention applicable } \\
\text { (Figure 5) }\end{array}$} \\
\hline 5 & Course not included & $2 \mathrm{CxRL}$ \\
\hline 7 & Posterior sinus & 1LCxR \\
\hline 13 & Posterior sinus & 2LCxR \\
\hline 24 & Posterior sinus & 1RLCx \\
\hline
\end{tabular}

\subsection{Leiden Convention Coronary Coding System}

According to the imaging Leiden Convention, the origin of the SCA was from the left-hand sinus (sinus 2) in 15 patients (71.4\%). In 13 patients, these single coronary arteries were also designated as originating from the left sinus in the Lipton classification; 2 could not be classified with Lipton. The origin of the SCA was from the right-hand sinus (sinus 1 ) in 6 cases $(28.5 \%)$, according to the Leiden Convention. This corresponded to the right sinus in the Lipton classification in 4 of these patients; 2 could not be classified according to Lipton. The imaging Leiden Convention could not be used in 11/32 patients (34\%): nine patients had pulmonary atresia/agenesis, and 2 patients had a common arterial trunk (1 Van Praagh type A1 and 1 with Van Praagh type A4 [7]) (Table 2). As these conditions do not allow to determine facing and non-facing sinuses, the Leiden Convention coronary coding system could not be used for these cases.

In summary, 10 patients $(10 / 32,31.25 \%)$ could not be classified with either the imaging Leiden Convention or Lipton classification (Table 2). Nine had pulmonary atresia, 1 had a truncus arteriosus Van Praagh type 4A, and in 6 of these, the origin of the SCA was from the anatomically posterior sinus, near the interatrial septum (Figure 6). Four patients, 2 with TGA and 2 with double outlet right ventricle, could be classified by the Leiden Convention, but not by Lipton classification, and 1 patient could be classified by Lipton classification, but not by the Leiden Convention (Figure 5, Table 2). This was a patient with a truncus arteriosus Van Praagh type A1. 


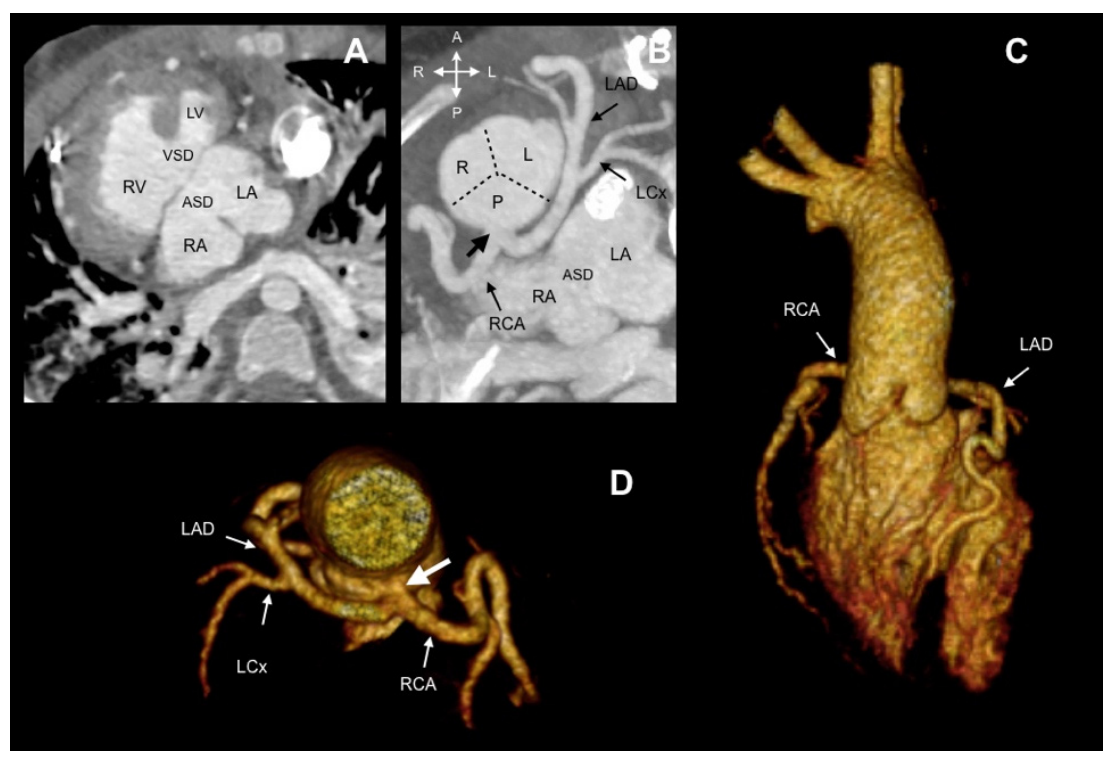

Figure 6. Case 17. A 10-year-old child with pulmonary atresia and common atrioventricular canal type C of Rastelli. (A) Oblique axial view showing atrial situs inversus, common atrioventricular connection, atrial and ventricular septal defect. (B) The SCA (thick arrow) arises from the posterior sinus, which gives origin to the RCA and left main stem. (C,D) A 3D volume-rendered image showing a posterior SCA. Ao: Aorta. ASD: Atrial septal defect. LA: Left atrium. LAD: Left anterior descending coronary artery. LCx. Left circumflex. LV: Left ventricle. NF: Non-facing sinus. RA: Right atrium. RCA: Right coronary artery. RV: Right ventricle. VSD: Ventricular septal defect.

\section{Discussion}

We present a case series of SCA diagnosed with CCTA in a tertiary referral center. To our knowledge, this represents the largest cohort of SCA reported based on CT. The CCTA allows accurate non-invasive evaluation of the coronary ostial morphology, course, and distribution area of the coronary arteries. This might be a result of the type of institution we represent, i.e., a nationwide cardiovascular referral center for complex congenital heart disease, that may show a higher prevalence of SCA as compared to the population without structural cardiac defects. In addition, the higher prevalence of the anomaly when compared to invasive angiography might be the result of the multiplanar capabilities of CT when compared to a biplanar method with limited visualization of spatial relationships.

Coronary artery anomalies are potentially relevant findings during surgery and for coronary intervention planning. In terms of clinical diagnosis, in our series, this finding was incidental in all cases. Although none of the adult patients in this study had significant atherosclerotic disease, the detection of atherosclerosis in an SCA is important because of the potential clinical implications of significant coronary artery disease in a single vessel providing the entire myocardial blood flow. In addition, relevance of its diagnosis also lies in the fact that this anomaly may cause myocardial ischemia by different mechanisms: due to angulations or abnormal courses that may affect the distribution of blood flow, even in the absence of atherosclerotic coronary lesions [2,8-10].

Of the 32 patients included, only $4(12.5 \%)$ showed an interarterial course. This variation might increase the risk of a major cardiac event, due to potential hemodynamic compromise. This prevalence is similar to previous reports [10,11]. Additionally, it is worthwhile to notice that approximately one third of the patients had an additional anomalous coronary branching pattern. In our series, associated CHD was found in almost $87.5 \%$ of cases, and concomitant anomalies in coronary arterial branching patterns were present in $31.25 \%$ of the patients.

Knowledge of anatomical variations in the origin and course of the coronary arteries in patients with CHD is essential to achieve optimal surgical preparation and follow up. 
Coronary classification systems are useful tools to detail important information about coronary anomalies to cardiologists, radiologists and cardiac surgeons.

Lipton classification was originally designed for patients with normal cardiac anatomy without additional congenital cardiac anomalies and is based on classifying the coronary artery as left or right, based on the spatial position (i.e., left or right) of the sinuses of Valsalva from which they emerge. To assign the branching pattern to a group, the system takes into account the coronary artery course relative to the pulmonary artery [2,3], which one might extend to the course around the right ventricular outflow tract for practical reasons. However, this limits their use in hearts with a rotated orientation of the great arteries (described as a general feature in congenital malformation of the outflow tract [12]) or pulmonary atresia. Another limitation of Lipton classification is that it contains a pre-set array of variations, leaving no room for anatomical variations outside this set. However, for many cases, the variations described by Lipton et al. are sufficient. An advantage with respect to the Leiden Convention is that posterior, anterior and septal courses of the coronary artery are directly included in the annotation and not only an interarterial course.

The Leiden Convention coronary coding system was developed to avoid using terms referring to the spatial anatomical position, such as left, right, posterior and anterior, which might be ambiguous in cases with malposition of the great arteries; herein lies its strength for use in (complex) CHD. In Lipton classification, the posterior sinus would, in many cases, correspond to the non-facing sinus in the Leiden Convention, which does not carry a coronary artery. However, especially in malrotation of the great arteries, this correspondence of the posterior sinus to the non-facing sinus is not obligatory.

The nomenclature of the sinuses of the Leiden Convention allows its use also in cases with congenital heart disease and malposition of the great arteries, regardless of the position of the great arteries and the spatial position of the sinuses of Valsalva. As the recognition of facing and non-facing sinuses is a prerequisite of the Leiden Convention coronary coding system, in principle, it cannot be used in cases of common arterial trunk, pulmonary atresia, cases with uni/quadri/pentacuspid valves or if the valve morphology cannot be distinguished [4,5]. The Leiden Convention also cannot be used if the coronary artery arises from the non-facing sinus. We have, to date, not encountered this situation in humans.

Neither the Leiden Convention nor Lipton classification could be applied in 10 patients (Table 2). Nine patients had pulmonary atresia and one patient had a common trunk Van Praagh type A4. For application of the Lipton classification, the SCA has to course around the pulmonary trunk or right ventricular outflow tract, so in the absence of a pulmonary trunk, such as in cases of pulmonary atresia, Lipton classification cannot be used. In addition, cases with the SCA originating from the posterior sinus make Lipton classification inapplicable. A coronary artery originating from a non-facing sinus is extremely rare, and we, therefore, do not consider the posterior sinus to be the equivalent of the non-facing sinus in these cases.

In some cases of pulmonary atresia where a small pulmonary trunk can be visualized, the Leiden Convention might still be applicable. However, we believe that in highly complex CHD where the coronary anatomy cannot be adequately described according to a classification system, it is better to provide a detailed description, including the origin, course (especially important in the case of the interarterial course), coronary artery dominance, the relationship relative to the position of the great vessels, as well as, in particular cases, the shape of the coronary orifice, acute angle take-off, or presence of myocardial bridging of a coronary artery. This corresponds to the "associated anomalies" step of the Leiden Convention coronary coding system. 


\section{Study Limitations}

This a retrospective study including patients for whom CCTA was performed on a variety of indications. Therefore, not all scans were made in an ECG triggered way that would be optimal for evaluation of the coronary anatomy. This may have hampered an optimal evaluation in some of the cases described.

\section{Conclusions}

Both Lipton classification and the Leiden Convention are useful to present important information about coronary anomalies. In complex CHD with an abnormal position of the great arteries, the Leiden Convention is better applicable. As expected, Lipton classification, which was principally developed for cases without structural heart disease, is less suitable for complex CHD with abnormal position of the great arteries. In pulmonary atresia, the use of both systems is limited. In such cases, it is recommended to provide a detailed description of the coronary anatomy as well as associated characteristics that might affect treatment planning and prognosis.

Author Contributions: Conceptualization, D.I.K.-T., M.J.-S., E.K.-H.; methodology, D.I.K.-T., M.J.-S., C.J.K., M.R.M.J. and E.K.-H.; validation, D.I.K.-T., C.J.K., M.R.M.J. and H.W.V.; formal analysis, D.I.K.-T. and C.J.K.; investigation, D.I.K.-T. and C.J.K.; data curation, D.I.K.-T., C.J.K. and M.R.M.J.; writing-original draft preparation, D.I.K.-T., M.J.-S., F.C.-C., M.D.-Z. and E.K.-H.; writing-review and editing, D.I.K.-T., M.J.-S., C.J.K., M.R.M.J. and E.K.-H.; visualization, D.I.K.-T. and C.J.K. All authors have read and agreed to the published version of the manuscript.

Funding: This research received no external funding.

Institutional Review Board Statement: Ethical review and approval were waived, due to the design of the study. However, it is worth mentioning that all patients in our institution signed a consent form that includes an approval to use their imaging information for academic purposes in those cases where retrospective studies are performed.

Informed Consent Statement: Informed consent was obtained from all subjects involved in the study.

Conflicts of Interest: All authors declare no conflict of interest. This research did not receive any specific grant from funding agencies in the public, commercial, or not-for-profit sectors.

\section{References}

1. Aldana-Sepulveda, N.; Restrepo, C.S.; Kimura-Hayama, E. Single coronary artery: Spectrum of imaging findings with multidetector CT. J. Cardiovasc. Comput. Tomogr. 2013, 7, 391-399. [CrossRef] [PubMed]

2. Lipton, M.J.; Barry, W.H.; Obrez, I.; Silverman, J.F.; Wexler, L. Isolated single coronary artery: Diagnosis, angiographic classification, and clinical significance. Radiology 1979, 130, 39-47. [CrossRef] [PubMed]

3. Yamanaka, O.; Hobbs, R.E. Coronary artery anomalies in 126,595 patients undergoing coronary arteriography. Catheter. Cardiovasc. Diagn. 1990, 21, 28-40. [CrossRef] [PubMed]

4. Gittenberger-de Groot, A.C.; Sauer, U.; Oppenheimer-Dekker, A.; Quaegebeur, J. Coronary arterial anatomy in transposition of the great arteries: A morphologic study. Pediatr. Cardiol. 1983, 4, 15-24.

5. Gittenberger-de Groot, A.C.; Koenraadt, W.M.C.; Bartelings, M.M.; Bökenkamp, R.; DeRuiter, M.C.; Hazekamp, M.G.; Bogers, A.; Quaegebeur, J.M.; Schalij, M.J.; Vliegen, H.W.; et al. Coding of coronary arterial origin and branching in congenital heart disease: The modified Leiden Convention. J. Thorac. Cardiovasc. Surg. 2018, 156, 2260-2269. [CrossRef] [PubMed]

6. Koppel, C.J.; Vliegen, H.W.; Bökenkamp, R.; Ten Harkel, A.D.J.; Kiès, P.; Egorova, A.D.; Jukema, J.W.; Hazekamp, M.G.; Schalij, M.J.; Gittenberger-de Groot, A.C.; et al. The Leiden Convention coronary coding system: Translation from the surgical to the universal view. Eur. Heart J. Cardiovasc. Imaging 2021. [CrossRef] [PubMed]

7. Van Praagh, R.; Van Praagh, S. The anatomy of common aorticopulmonary trunk (truncus arteriosus communis) and its embryologic implications. A study of 57 necropsy cases. Am. J. Cardiol. 1965, 16, 406-425. [CrossRef]

8. De Agustín, J.A.; Marcos-Alberca, P.; Manzano Mdel, C.; Fernández-Golfín, C.; Pérez de Isla, L.; Hernández Antolín, R.; Macaya, C.; Zamorano, J. Percutaneous Intervention in a single coronary artery: Evaluation of multislice tomography and its feasibility. Rev. Esp. Cardiol. 2010, 63, 607-611. [CrossRef]

9. Mandal, S.; Tadros, S.S.; Soni, S.; Madan, S. Single coronary artery anomaly: Classification and evaluation using multidetector computed tomography and magnetic resonance angiography. Pediatr. Cardiol. 2014, 35, 441-449. [CrossRef] [PubMed]

10. Villa, A.; Sammut, E.; Nair, A.; Rajani, R.; Bonamini, R.; Chiribiri, A. Coronary artery anomalies overview: The normal and the abnormal. World J. Radiol. 2016, 8, 537-555. [CrossRef] [PubMed] 
11. Zhou, Z.; Xu, L.; Zhang, N.; Wang, H.; Liu, W.; Sun, Z.; Fan, Z. CT coronary angiography findings in non-atherosclerotic coronary artery diseases. Clin. Radiol. 2018, 73, 205-213. [CrossRef] [PubMed]

12. Houyel, L.; Bajolle, F.; Capderou, A.; Laux, D.; Parisot, P.; Bonnet, D. The pattern of the coronary arterial orifices in hearts with congenital malformations of the outflow tracts: A marker of rotation of the outflow tract during cardiac development? J. Anat. 2013, 222, 349-357. [CrossRef] [PubMed] 